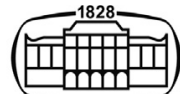

AKADÉMIAI KIADÓ

Developments in Health Sciences

2 (2019) 4, 104-107

DOI:

$10.1556 / 2066.2019 .00005$

(c) 2019 The Author(s)

\section{ORIGINAL ARTICLE}

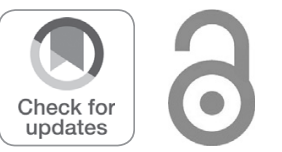

*Corresponding author. Faculty of Health Science, Semmelweis University, Vas utca 17, Budapest, H1088, Hungary.

E-mail: kovacse@se-etk.hu

\section{Factors associated with postural control in nursing home residents}

\author{
Oral presentation at the 13th Conference of the Hungarian \\ Medical Association of America - Hungary Chapter (HMAA-HC) \\ at 30-31 August 2019, in Balatonfüred, Hungary
}

\author{
R.L. ERDÖS ${ }^{1}$ I. JÓNÁSNÉ SZTRUHÁR ${ }^{2,3}$, A. SIMON ${ }^{2}$ and \\ É. KOVÁCS ${ }^{1 *}$
}

${ }^{1}$ Department of Morphology and Physiology, Faculty of Health Sciences, Semmelweis University, Budapest, Hungary

${ }^{2}$ Department of Physiotherapy, Faculty of Health Sciences, Semmelweis University, Budapest, Hungary

${ }^{3}$ Old Age Home of the Municipality of Budapest, Budapest, Hungary

Received: September 30, 2019 • Revised manuscript received: December 16, 2019 • Accepted: February 24, 2020 Published online: July 31, 2020

\begin{abstract}
Purpose: Decline of the sensory and motor systems in older people negatively affects postural control. This increases the risk of falls, which is dangerous for older people in long-term care. Being aware of the quality of postural control and the factors affecting it among elderly people, is crucial in implementing an effective fall-prevention program. This study aimed to measure postural control and the demographic, health-related, and functional factors presumed to be correlated with it among nursing home residents. Another aim was to find valid screening tools based on these factors. Materials and methods: Seventy one nursing home residents were included. Postural control was measured using the Berg Balance Scale. Grip strength, the 30-s chair stand test, and the Timed Up and Go test were used to measure global muscle strength, and functional mobility, respectively. The results of these functional tests were dichotomized using age-specific reference values. Results: Postural control was significantly worse in those who did not reach the age-specific reference values in any of the three functional tests. Effect sizes were large for functional mobility and medium for muscle strength. Multimorbidity and gender had no effect on postural control in our sample. Conclusions: Among nursing home residents, postural control is related to functional mobility and muscle strength. Thus, routine testing of these skills among elderly people is an important task of the physiotherapist.
\end{abstract}

\section{KEYWORDS}

postural control, elderly, Berg Balance Scale, fall prevention

\section{INTRODUCTION}

Postural control, which is the basis of all human movement, compensates both the external forces acting on the body and internal forces occurring during movements [1]. The success of postural control depends on the integrity and efficiency of multiple organ systems: based on sensory information, the nervous system perceives and evaluates the spatial position of the body under both static and dynamic conditions. In this way, postural control continually adjusts body posture according to the purpose of the movements [2]. 
In the elderly, due to the functional decline of sensory and motor systems, perception of the body's spatial position, and the associated motor response, are delayed and inaccurate [3]. As a result, older adults feel their balance is unstable, which may lead to a further decline in postural control and an increased risk of falls [4].

Improving postural control of the elderly is an essential component of many fall-prevention exercise programs. They are most effective if we involve older people at risk as early as possible [5].

For this purpose, we need to be aware how postural control can be assessed. With the help of the Berg Balance Scale (BBS), both the static and dynamic components of postural control can be examined in detail $[6,7]$. So far, the BBS has been used on either community-living older people or a heterogeneous sample of community-living and institutionalized older people. In these populations, the postural control measured by the Berg Balance Scale has definitely correlated with functional mobility and gender $[6,8]$.

However, we do not know how functional mobility and gender, as well as global muscle strength and multimorbidity, are related to postural control among older people living in long-term care institutions. A further aim of our cross-sectional study was to find valid tools that can be used to screen for those in need of further examination and targeted therapy.

We hypothesized that postural control has a relation with or correlates with functional abilities, including functional mobility, global muscle strength of the upper and lower body, gender, and multimorbidity. We also hypothesized that our independent variables could be used to discover valid screening factors.

\section{MATERIALS AND METHODS}

\section{Sampling}

We enrolled participants on a voluntary basis who lived in a long-term care institute in Budapest, Hungary. Their anonymity was ensured. Participants were included if they were 60 years of age or above and were able to walk at least $6 \mathrm{~m}$ with or without walking aid. They were excluded if they had lived in the nursing home for less than two months, were unable to perform tests, or had communication difficulties. Based on these criteria, we enrolled 71 elder participants in the research.

This cross-sectional study was conducted in 2017 in accordance with the 2008 revision of the 1975 Declaration of Helsinki.

\section{Measurements}

Demographic and medical data were collected from health records.

The participants' postural control was measured using the BBS, which measures 14 tasks on a 5-point scale. The tasks of the BBS simulate common, daily-life situations. The maximum score that can be achieved is 56 , which refers to a perfect balance. The cut-off value is 45 points, which indicates an increased risk of falls in the elderly $[6,9]$.

Global muscle strength of the upper body was evaluated by measuring hand-grip force in kilogrammes with a Kern MAP 40K1 dynamometer. In fact, hand grip force closely correlates with over-all muscle strength. The test was administered in a sitting position by taking the average of two consecutive measurements in the dominant hand [10].

Standard risings during the 30 -s chair-stand test were counted to measure global muscle strength of the lower body. Participants were asked - after hearing the word "go" - to rise from a chair (approximate seat height of $46 \mathrm{~cm}$ ) and sit down, with arms crossed at forearms and held against the chest, as many times as possible in 30 seconds. During testing, participants wore their regular footwear. If the participant was more than halfway up when the 30 seconds had elapsed, it counted as a full stand [11].

To measure functional mobility, the Timed Up and Go (TUG) test was performed. This test measures the time needed for a participant to stand up from a standard arm chair (approximate seat high of $46 \mathrm{~cm}$, arm height $65 \mathrm{~cm}$ ), to walk for $3 \mathrm{~m}$ with a comfortable but secure pace, and to turn and walk back and sit down in the chair. Participants were allowed to use the arms when standing up and to use a walking aid, if needed. They were also allowed to wear their regular footwear. A stopwatch was started on the "go" and stopped when the participant had returned to a fully sitting position, with back against the backrest. Two consecutive trials were averaged. Between the trials there was a $30-\mathrm{s}$ rest time, if needed [12].

\section{Statistical analysis}

To describe our sample, we calculated means (with standard deviations) or absolute and relative frequencies. The relationships between variables were analysed with independent samples t tests. The results of the functional tests were dichotomized based on the age-related normative value [1315]. The strengths of significant correlations were interpreted based on Cohen's d value. A Cohen's d value of 1.3 was regarded as very large, 0.8 as large, 0.5 as medium, and 0.2 as small [16].

\section{RESULTS}

The mean age of the sample was 73, the percentage of female participants was $70 \%(n=73) .28$ participants had hypertension, 24 had musculoskeletal disorders, 20 had cardiopulmonary disease, 18 had a history of cerebral involvement, and 13 suffered from diabetes. The mean performance on the BBS was 46.5 points.

A total of 46 subjects (65\%) had below the 45 -points cutoff value, indicating risk of falls. They would need early targeted therapy to improve balance particularly.

Scores on the BBS were significantly lower in those whose functional mobility did not reach age-specific reference values published in the literature. Scores on the BBS 
were also lower for those older adults whose muscle strength in both upper and lower body was worse than age-related normative values.

The effect sizes showed a large effect of functional mobility $(d=1.4)$, and a medium effect of upper $(d=0.65)$ and lower body muscle $(d=0.71)$. This meant that the poorer the functional mobility of the elderly people and the weaker their muscles, the more uncertain their postural control was. The effects of gender and multimorbidity were not confirmed by our study in this population.

Significant effects were demonstrated relating to functional mobility and muscle strength. In accordance with the purpose of our study - as a validity indicator regarding these two factors - the sensitivity of our measurement tools was calculated by cross-table analysis [17]. We calculated the sensitivity in order to assess the validity of these three easyto-perform tests. The sensitivity of these tests is the ability to reliably identify those people whose results in the BBS are below the cut-off value.

The sensitivity of the 30 -s chair-stand test is $84 \%$, which means that it can screen more than $4 / 5$ (four-fifths) of the elderly people at fall risk. The TUG test has similar sensitivity, whereas the grip-strength test can identify almost $2 / 3$ of the elderly who need further examination and targeted therapy (sensitivity: 63\%).

\section{DISCUSSION AND CONCLUSIONS}

In our study, conducted among long-term-care institution residents, we investigated the relationships postural control has with functional mobility, global muscle strength of the upper and lower body, multimorbidity, and gender. The large effect of functional mobility and the moderate effect of muscle strength were demonstrated. The effect of the gender and multimorbidity were not demonstrated in our sample.

The results of our research are in line with those of international research in many respects.

Functional mobility has been shown to be strongly related to postural control in a sample of community-living older people as well as a heterogeneous sample of elderly people $[6,8,18]$.

We investigated the role of the gender in postural control because, according to the literature [19], gender is an intrinsic fall-risk factor. There are $67 \%$ more nonfatal falls among older female adults than among males. We wanted to examine whether there is a difference in postural control between female and male older people. The relationship between postural control and gender has been examined by only one study. This study, in accordance with ours, could not prove this relationship [8].

We examined the effects of global muscle strength in both the upper and lower body, and they were found to be significant $[19,20]$.

We examined the effect of multimorbidity, but it was not found to be significant. We also demonstrated that the easyto-perform TUG test and the global muscle strength tests are able to identify those elderly who need further examination and intervention.

Our results demonstrate that postural control of people living in long-term care institutions is not related to multiple morbidities, but it is related to functional mobility and muscle strength. Consequently, physiotherapists are especially responsible for measuring the latter factors in these people, screening those who need more detailed examinations and, based on the results, determining whether they need a targeted balance program as soon as possible. The principles of the programs focussing on improvement of postural control in this population are excellently summarized in a meta-analysis [21].

\section{LIST OF ABBREVIATIONS}

\author{
TUG Timed Up and Go
}

BBS Berg Balance Scale

Ethical approval: This study was conducted in accordance with the 2008 revision of the 1975 Declaration of Helsinki.

Authors' contribution: ÉK and RLE summarized the scientific background of the paper, ISZJ, RLE collected the data and performed the necessary calculations, ÉK carried out the statistical analyses, ÉK, RLE, and AS finalized the text.

Conflicts of interest/Funding: The authors declare no conflict of interest and no financial support was received for this study.

Acknowledgements: We thank all participants for their contribution in the study.

\section{REFERENCES}

1. Pollock AS, Durward BR, Rowe PJ, Paul JP. What is balance? Clin Rehabil 2000;14(4):402-6. https://doi.org/10.1191/0269215500cr342oa.

2. Horak FB. Postural orientation and equilibrium: what do we need to know about neural control of balance to prevent falls? Age Ageing 2006;35(Suppl. 2):7-11. https://doi.org/10.1093/ageing/afl077.

3. Laughton CA, Slavin M, Katdare K, Nolan L, Bean JF, Kerrigan DC, Aging, muscle activity, and balance control: physiologic changes associated with balance impairment. Gait Posture 2003;18(2): 101-8. https://doi.org/10.1016/S0966-6362(02)00200-X.

4. Horlings CG, van Engelen BG, Allum JH, Bloem BR. A weak balance: the contribution of muscle weakness to postural instability and falls. Nat Clin Pract Neurol 2008;4(9):504-15. https://doi.org/ 10.1038/ncpneuro0886.

5. Howe TE, Rochester L, Jackson A, Banks PMH, Blair VA. Exercise for improving balance in older people. Cochrane Database Syst Rev 2011;9;(11):CD004963. https://doi.org/10.1002/14651858.CD004963. pub3. 
6. Berg K, Wood-Dauphinee S, Williams JI, Gayton D. Measuring balance in the elderly: preliminary development of an instrument. Physiotherapy Canada 1989;41:304-11. https://doi.org/10.3138/ptc.41. 6.304 .

7. Fábián G. Állapotfelmérő eszközök az idősgondozásban [Health assessment tools for elderly care]. 1st ed. Debrecen: Debreceni Egyetemi Kiadó; 2014.

8. Halsaa KE, Brovold T, Graver V, Sandvik L, Bergland A. Assessments of interrater reliability and internal consistency of the Norwegian version of the Berg Balance Scale. Arch Phys Med Rehabil 2007;88(1):94-8.

9. Neuls PD, Clark TL, Van Heuklon NC, Proctor JE, Kilker BJ, Bieber ME, Usefulness of the Berg Balance Scale to predict falls in the elderly. J Geriatr Phys Ther 2011;34(1):3-10. https://doi.org/10. 1097/JPT.0b013e3181ff2b0e.

10. Roberts HC, Denison HJ, Martin HJ, Patel HP, Syddall H, Cooper $\mathrm{C}$, A review of the measurement of grip strength in clinical and epidemiological studies: towards a standardised approach. Age Ageing 2011;40(4):423-9. https://doi.org/10.1093/ageing/afr051.

11. Jones CJ, Rikli RE, Beam WC. A 30-s chair-stand test as a measure of lower body strength in community-residing older adults. Res Q Exerc Sport 1999;70(2):113-9.

12. Podsiadlo D, Richardson S. The timed "Up \& Go": a test of basic functional mobility for frail elderly persons. J Am Geriatr Soc 1999; 39(2):142-8.

13. Whitney JC, Lord SR, Close JC. Streamlining assessment and intervention in a falls clinic using the timed up and go test and physiological profile assessments. Age Ageing 2005;34(6): 567-71.

14. Dodds RM, Syddall HE, Cooper R, Benzeval M, Deary IJ, Dennison EM, Grip strength across the life course: normative data from twelve British studies. PLoS One 2014;9:e113637. https://doi.org/10. 1371/journal.pone.0113637.

15. Rikli RE, Jones CJ. Functional fitness normative scores for community-residing older adults, ages 60-94. J Aging Phys Activity 1999;7(2):162-81. https://doi.org/10.1123/japa.7.2.162.

16. Sullivan GM, Feinn R. Using effect size-or why the $\mathrm{p}$ value is not enough. J Grad Med Educ 2012;4(3):279-82. https://doi.org/10. 4300/JGME-D-12-00156.1.

17. Prohászka Z, Füst Gy, Dinya E. Biostatisztika a klinikumban [Biostatistics in the clinic]. Budapest: Semmelweis Kiadó; 2009.

18. Sahin F, Yilmaz F, Ozmaden A, Kotevolu N, Sahin T, Kuran B. Reliability and validity of the Turkish version of the Berg Balance Scale. J Geriatr Phys Ther 2008;31(1):32-7.

19. Fabre JM, Ellis R, Kosma M, Wood RH. Falls risk factors and a compendium of falls risk screening instruments. J Geriatr Phys Ther 2010;33(4):184-97.

20. Chou CY, Chien CW, Hsueh IP, Sheu CF, Wang CH, Hsieh CL. Developing a short form of the Berg Balance Scale for people with stroke. Phys Ther 2006;86(2):195-204. https://doi.org/10.1177/ 1545968306289297.

21. Sherrington C, Tiedemann A, Fairhall N, Close JC, Lord SR. Exercise to prevent falls in older adults: an updated meta-analysis and best practice recommendations. N S W Public Health Bull 2011;22(3-4):78-83. 